\title{
Antioxidant action of phenols: Revisiting theoretical calculations of their thermodynamics
}

\author{
Monika Biela, Bernadeta Pelikánová, Martin Michalík \\ Department of Chemical Physics, Slovak University of Technology in Bratislava, \\ Radlinského 9, SK-812 37 Bratislava, Slovakia \\ monika.biela@stuba.sk
}

\begin{abstract}
Theoretical prediction ability of M06-2X functional was tested for thermodynamics of phenol, 15 para and 15 meta phenol derivatives. Calculations were done for gas phase as well as for polar and nonpolar solvents. Although predicted values might be shifted from the experimental ones in the framework of the employed DFT functional and basis set, the calculated and experimental data sets correlate well together. Very good linearity was found especially for the correlation of experimental and theoretical proton affinities. Hammett type correlations between the environments considered were compared. The phenolic $\mathrm{C}-\mathrm{O}$ bond length was also tested as an alternative substituent effect descriptor while the type and position of the functional group on the aromatic ring have a direct effect on the phenolic bond.
\end{abstract}

Keywords: DFT, Hammett constants, M06-2X functional, reaction enthalpy

\section{Introduction}

Phenols are considered as antioxidants providing protection against free radicals and as such are often utilized in forms of various derivatives. Over the last few years, three main mechanisms of radical scavenging action were proposed as shown in Fig. 1. While the final product remains the same in all of them, the number of steps and intermediates as well as the solvent preference differ. Comprehensive description of illustrated reaction paths can be found elsewhere (Rimarčík et al., 2011).

Historically, Bond Dissociation Enthalpy (BDE) is one of the earliest studied quantity in association with antioxidants with straightforward mechanism. On the other hand, the first steps in latter mechanisms are often more interesting in the kinetic studies owing to their rate-determining nature. Specifically, the ionization potential (IP) or anion proton affinity $(\mathrm{PA})$ values are usually higher than those of Proton Dissociation Enthalpy (PDE) or Electron Transfer Enthalpy (ETE).

Although there have been many theoretical studies regarding antioxidant action of substituted phenols, very few of them employ M06-2X functional of the Truhlar group (Zhao et al., 2008) and even fewer of them determine solvent effects. On the other hand, there are many studies using B3LYP functional (Klein et al., 2009; Vagánek et al., 2011; Chen et al., 2015). Some of the studies are focused mainly on the HAT mechanism, correlation between $\mathrm{BDEs}$ or $\mathrm{C}-\mathrm{O}$ bond lengths and Hammett constants (Klein et al., 2006b). Complex thermodynamics of three main mechanisms is included in other studies (Klein et al., 2006a; Chen et al., 2015).

In contrast to popular B3LYP published in 1988, M06-2X is a more recent global hybrid functional with higher (54\%) Hartree-Fock exchange. It is advertised as one of the top performers and

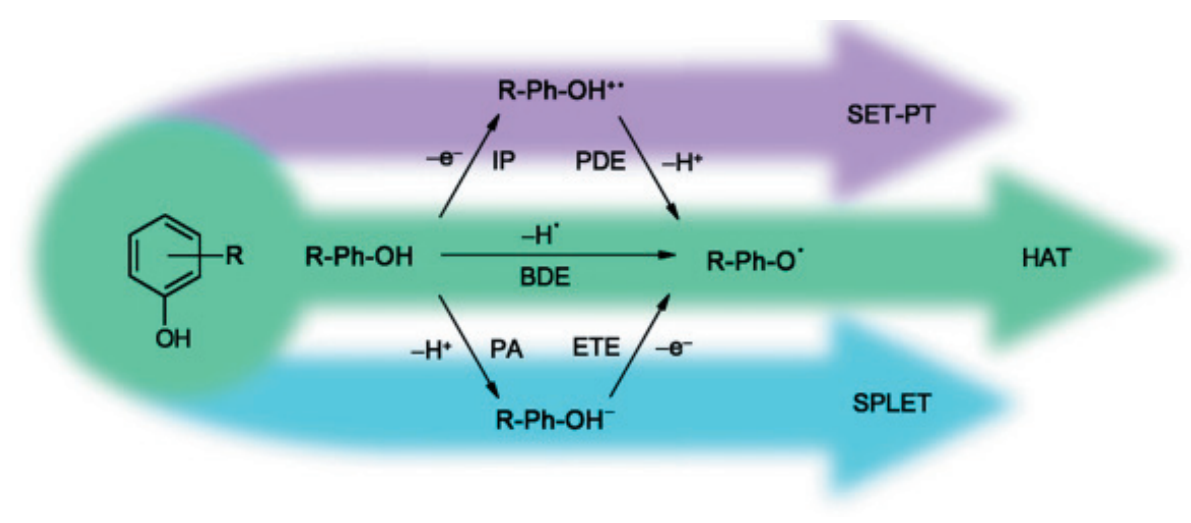

Fig. 1. Main mechanisms of antioxidant action - Sequential Electron Transfer Proton Transfer (SETPT), Hydrogen Atom Transfer (HAT) and Sequential Proton Loss Electron Transfer (SPLET). 
should be optimized for thermodynamics calculations (Zhao and Truhlar, 2008). Numerous validation studies (Huang et al., 2014; Luo et al., 2011) put this Minnesota 06 functional in a position superior to B3LYP. It should also outperform other DFT methods providing better description of medium-range exchange-correlation energies. Nevertheless, it has to be mentioned that the vast majority of benchmark studies perform statistics based on single point energies with so-called reference theoretical data (mostly from gas-phase coupled cluster calculations). However, the goal of all computational methods is to provide data as close to the experimental ones as possible. Also, the geometries are usually not optimized employing the DFT functional but rather just taken from MP2 of more precise calculations. In our case of monosubstituted phenols, experimental data on thermodynamics are available and thus a more relevant correlation can be done. Parameters from linear regression can be then employed for reactivity prediction. Therefore, the main goals of this work are: a) to perform geometry optimization of phenol, 15 para and 15 meta phenol derivatives (see Tables 1-2) using M06-2X functional, b) to investigate the rate determining reaction enthalpies of antioxidant mechanism for the studied compounds, c) to compare the obtained results with experimental data, and d) to find relationships between Hammett constants and reaction enthalpies.

\section{Computational details}

All geometry optimizations were performed in the Gaussian 16 program package (Frisch et al., 2016) at DFT level of theory with the M06-2X (Zhao et al., 2008) hybrid functional as implemented in Gaussian. Energy cut-off was $10^{-5} \mathrm{~kJ} \mathrm{~mol}^{-1}$ and final RMS energy gradient was below $0.01 \mathrm{~kJ} \mathrm{~mol}^{-1} \mathrm{~A}^{-1}$. For all atoms, triple zeta $6-311++\mathrm{G}(\mathrm{d}, \mathrm{p})$ basis sets were employed (Hariharan et al., 1973; Rassolov et al., 1998). The chosen basis sets are assumed to provide reliable molecular geometries and reaction enthalpies and are generally considered to be sufficiently large (Michalík et al., 2014; Škorňa et al., 2014). Influence of the water and benzene solvents was approximated by implicit continuum model SMD (Marenich et al., 2009). The optimized structures were confirmed to be real minima by vibrational analysis (no imaginary frequencies).

Based on optimized structures, thermodynamic quantities for the processes mentioned in Fig. 1, i.e. bond dissociation enthalpies (BDE), ionization potentials (IP), anion proton affinity (PA) were calculated at room temperature as follows

$$
\begin{gathered}
\mathrm{BDE}=H\left(\mathrm{Ph}-\mathrm{O}^{\bullet}\right)+H\left(\mathrm{H}^{\bullet}\right)-H(\mathrm{Ph}-\mathrm{OH}) \\
\mathrm{IP}=H\left(\mathrm{Ph}-\mathrm{OH}^{\cdot+}\right)+H\left(\mathrm{e}^{-}\right)-H(\mathrm{Ph}-\mathrm{OH}) \\
\mathrm{PA}=H\left(\mathrm{Ph}-\mathrm{O}^{-}\right)+H\left(\mathrm{H}^{+}\right)-H(\mathrm{Ph}-\mathrm{OH})
\end{gathered}
$$

where $H(\mathrm{Ph}-\mathrm{OH})$ represents the total enthalpy of the phenol derivative, $H\left(\mathrm{Ph}-\mathrm{OH}^{\bullet+}\right)$ is the total enthalpy of the phenol radical cation, $H\left(\mathrm{Ph}-\mathrm{O}^{\bullet}\right)$ and $H\left(\mathrm{Ph}-\mathrm{O}^{-}\right)$are the total enthalpies of the phenoxy radical and the phenoxide anion, respectively. In water, enthalpy of proton $H\left(\mathrm{H}^{+}\right)$is $-1049.60 \mathrm{~kJ} \mathrm{~mol}^{-1}$, in benzene it is $-853.71 \mathrm{~kJ} \mathrm{~mol}^{-1}$. The latter was estimated as the enthalpy of the reaction $\mathrm{C}_{6} \mathrm{H}_{6}(\mathrm{l})+\mathrm{H}^{+}(\mathrm{g}) \rightarrow\left(\mathrm{C}_{6} \mathrm{H}_{6}\right)^{+}$(solv) in benzene. Enthalpy of hydrogen atom $H\left(\mathrm{H}^{\bullet}\right)$ in benzene is $-1301.02 \mathrm{~kJ} \mathrm{~mol}^{-1}$, in gas phase it is $-1301.81 \mathrm{~kJ} \mathrm{~mol}^{-1}$ and in water it is $-1296.26 \mathrm{~kJ} \mathrm{~mol}^{-1}$. Finally, the calculated enthalpy of electron $H\left(\mathrm{e}^{-}\right)$ in benzene is $-8.20 \mathrm{~kJ} \mathrm{~mol}^{-1}$ while in water it is $-74.75 \mathrm{~kJ} \mathrm{~mol}^{-1}$. All these values were also calculated in this study at the M06-2X/6-311++G** level.

Relevant values from the statistical analysis were rounded and are presented with the corresponding standard deviations of the last digit shown in parenthesis. The goodness of fit of a statistical model is characterized by correlation coefficient $\mathrm{R}$.

\section{Results and Discussion}

The main aim of our work was to predict experimental values as best as possible; therefore, the correlation between proton affinities measured on a pulsed ion cyclotron resonance (ICR) mass spectrometer (Fujio et al., 1981) and theoretical gas phase PAs were first investigated. This should proof that the employed DFT functional and basis set provide reliable results. PAs were chosen because, unlike other quantities, as many as 25 various meta and para phenol derivatives show gas phase acidity measured under the same experimental conditions. Tables 1 and 2 list gas phase and solvent phase values calculated in this study. Significant solvent dependence of proton affinity can be attributed mainly to substantial differences in proton enthalpy. Nevertheless, the correlation of 25 experimental PA(exp) values and the present $\mathrm{PA}(\mathrm{DFT})$ in gas phase show excellent linearity $(\mathrm{R}=0.998)$ and linear equation:

$$
\begin{gathered}
\mathrm{PA}(\exp ) / \mathrm{kJ} \mathrm{mol}^{-1}=0.12(2) \cdot 10^{3}+ \\
+0.92(2) \cdot \mathrm{PA}(\mathrm{DFT}) / \mathrm{kJ} \mathrm{mol}{ }^{-1}
\end{gathered}
$$

Prediction for other derivatives can be therefore made with great confidence using this equation. From Equation (4) it is evident that theoretical 
proton affinities are slightly underestimated with respect to the experimental absolute values. Very similar linearity $(\mathrm{R}=0.997)$ as well as slope of $0.90(2)$ and intercept of $0.15(3) \cdot 10^{3}$ were found in a previous study (Klein and Lukeš, 2006a) that employed B3LYP and the same basis set, 6-311++ *** $^{*}$.

On the other hand, experimental BDEs tend to vary quite wildly from one method to another (see e.g. the comparison in Klein and Lukeš, 2006b) making any direct comparison and data merging trouble- some. Thus, a comparison with electrochemical measurements done by Bordwell et al. (1991) compiling 21 experimental values was applied. M06-2X data correlate fairly well with $\mathrm{R}=0.968$ with the linear equation of:

$$
\begin{gathered}
\operatorname{BDE}(\exp ) / \mathrm{kJ} \mathrm{mol}^{-1}= \\
=0.06(2) \cdot 10^{3}+0.83(5) \cdot \operatorname{BDE}(\mathrm{DFT}) / \mathrm{kJ} \mathrm{mol}^{-1}
\end{gathered}
$$

The same correlation, but with B3LYP functional employed, results in the intercept of

Tab. 1. M06-2X/6-311++ $\mathrm{G}^{* *}$ thermodynamic quantities defined by Eqs. (1)-(3) for phenols substituted

\begin{tabular}{|c|c|c|c|c|c|c|c|c|c|}
\hline \multirow{2}{*}{$X$} & \multicolumn{3}{|c|}{ Water } & \multicolumn{3}{|c|}{ Benzene } & \multicolumn{3}{|c|}{ Gas } \\
\hline & BDE & PA & IP & BDE & $\mathbf{P A}$ & IP & BDE & PA & IP \\
\hline Br: & 385 & 150 & 692 & 374 & 453 & 728 & 374 & 1414 & 839 \\
\hline $\mathbf{C F}_{3}$ : & 387 & 149 & 697 & 376 & 449 & 744 & 377 & 1406 & 866 \\
\hline Cl: & 385 & 150 & 688 & 374 & 453 & 723 & 375 & 1419 & 838 \\
\hline CN: & 390 & 146 & 703 & 379 & 438 & 752 & 380 & 1394 & 880 \\
\hline F: & 384 & 151 & 687 & 374 & 457 & 725 & 375 & 1427 & 848 \\
\hline Me: & 373 & 162 & 660 & 366 & 482 & 689 & 368 & 1456 & 802 \\
\hline MeCO: & 385 & 154 & 687 & 374 & 464 & 723 & 376 & 1426 & 838 \\
\hline MeO: & 381 & 158 & 660 & 373 & 479 & 682 & 375 & 1451 & 792 \\
\hline $\mathrm{MeSO}_{2}:$ & 391 & 143 & 708 & 379 & 438 & 749 & 381 & 1391 & 867 \\
\hline $\mathrm{NH}_{2}:$ & 370 & 163 & 601 & 365 & 483 & 623 & 369 & 1459 & 742 \\
\hline $\mathrm{NMe}_{2}$ : & 370 & 164 & 579 & 365 & 487 & 591 & 369 & 1459 & 700 \\
\hline $\mathrm{NO}_{2}:$ & 396 & 145 & 715 & 381 & 430 & 764 & 381 & 1387 & 891 \\
\hline OH: & 376 & 157 & 656 & 368 & 471 & 687 & 369 & 1443 & 801 \\
\hline Ph: & 378 & 159 & 668 & 369 & 472 & 685 & 370 & 1437 & 785 \\
\hline$t$-But: & 376 & 164 & 664 & 367 & 483 & 688 & 369 & 1452 & 795 \\
\hline
\end{tabular}
with $X$ in meta position in various environments. All values are in $\mathrm{kJ} \mathrm{mol}^{-1}$.

Tab. 2. M06-2X/6-311++G** thermodynamic quantities defined by Eqs. (1)-(3) for phenols substituted

\begin{tabular}{|c|c|c|c|c|c|c|c|c|c|}
\hline \multirow{2}{*}{$X$} & \multicolumn{3}{|c|}{ Water } & \multicolumn{3}{|c|}{ Benzene } & \multicolumn{3}{|c|}{ Gas } \\
\hline & BDE & PA & IP & BDE & PA & IP & BDE & PA & IP \\
\hline Br: & 379 & 154 & 680 & 367 & 457 & 705 & 367 & 1419 & 811 \\
\hline $\mathbf{C F}_{3}$ : & 395 & 148 & 709 & 382 & 438 & 752 & 382 & 1396 & 871 \\
\hline Cl: & 377 & 154 & 675 & 365 & 459 & 704 & 366 & 1425 & 814 \\
\hline CN: & 395 & 138 & 709 & 381 & 421 & 752 & 380 & 1376 & 870 \\
\hline F: & 371 & 159 & 667 & 361 & 470 & 702 & 362 & 1441 & 819 \\
\hline Me: & 364 & 165 & 646 & 358 & 485 & 669 & 361 & 1459 & 780 \\
\hline MeCO: & 390 & 140 & 696 & 376 & 437 & 727 & 376 & 1394 & 837 \\
\hline MeO: & 341 & 162 & 610 & 342 & 490 & 636 & 346 & 1459 & 740 \\
\hline $\mathrm{MeSO}_{2}:$ & 400 & 137 & 720 & 383 & 424 & 760 & 386 & 1372 & 873 \\
\hline $\mathbf{N H}_{2}:$ & 320 & 171 & 564 & 324 & 496 & 584 & 332 & 1468 & 696 \\
\hline $\mathrm{NMe}_{2}:$ & 315 & 168 & 548 & 319 & 487 & 555 & 327 & 1455 & 659 \\
\hline $\mathrm{NO}_{2}:$ & 403 & 122 & 728 & 386 & 401 & 778 & 387 & 1354 & 900 \\
\hline OH: & 350 & 167 & 622 & 344 & 486 & 651 & 347 & 1461 & 760 \\
\hline Ph: & 367 & 158 & 644 & 359 & 462 & 655 & 361 & 1426 & 750 \\
\hline$t$-But: & 366 & 165 & 649 & 359 & 484 & 671 & 362 & 1453 & 773 \\
\hline H: & 377 & 160 & 671 & 368 & 477 & 703 & 370 & 1453 & 818 \\
\hline
\end{tabular}
with $X$ in para position in various environments. All values are in $\mathrm{kJ} \mathrm{mol}^{-1}$. 


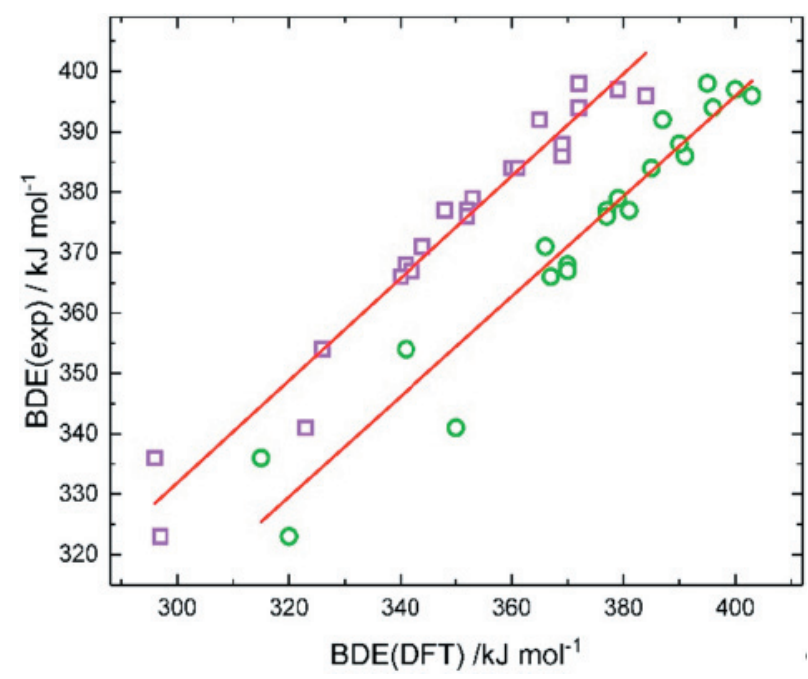

Fig. 2. Correlation between experimental (Bordwell et al., 1991) bond dissociation enthalpies BDE(exp) and theoretical BDE(DFT). Relationship with B3LYP data (Klein and Lukeš, 2006b) is represented by violet squares, green circles represent M06-2X data of this study.

$0.08(2) \cdot 10^{3} \mathrm{~kJ} \mathrm{~mol}^{-1}$, provided virtually the same slope of $0.85(4)$ and slightly better correlation coefficient $\mathrm{R}=0.978$. The linear trends are plotted and compared graphically in Fig. 2.

Gas phase ionization potential measurements are laborious requiring costly apparatus therefore compilations of more than few derivatives are scarce. Experimental data of more than ten works was summarized by Klein and Lukeš, 2006c. The authors found theoretical B3LYP ionization potentials rather shifted from experimental values but substituent induced changes were well predicted. On the other hand, M06-2X values are closer to the experimental ones with relatively good correlation coefficient of $\mathrm{R}=0.964$. Regression analysis provided the linear equation of:

$$
\begin{gathered}
\mathrm{IP}(\exp ) / \mathrm{eV}= \\
=0.3(6)+0.98(7) \cdot \mathrm{IP}(\mathrm{DFT}) / \mathrm{eV}
\end{gathered}
$$

In analogous correlation with B3LYP data the slope reached 1.00(9) which is still within M06$2 \mathrm{X}$ interval. The shift of B3LYP values is best resembled by intercept of 2.0(6) and slightly worse correlation $(\mathrm{R}=0.935)$ shown in Fig. 3.

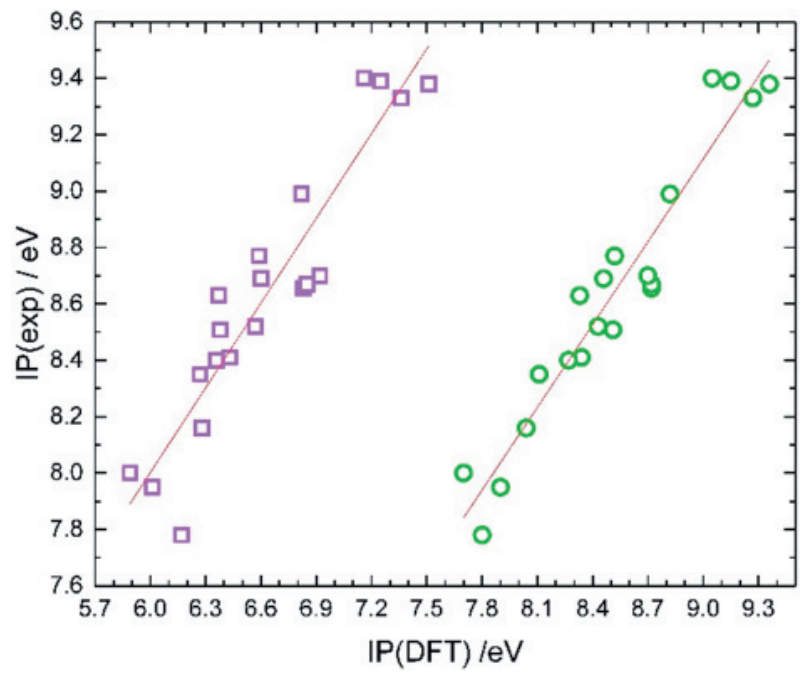

Fig. 3. Correlation between experimental ionization potentials IP(exp) compiled by Klein and Lukeš, 2006c and theoretical IP(DFT). Relationship with B3LYP data is represented by violet squares, green circles represent M06-2X data of this study.

Hammett type correlations were explored next as an, to some extent, pseudo-validation tool. In the study of benzoic acids ionization, Hammett proposed (Hammett, 1937) substituent-specific constant $\sigma$ as a reliable substituent effect descriptor. This constant remains popular up to now, finding its use in various correlations including derivatives far beyond benzoic acids. Prediction of equilibrium and rate constants for different types of reactions can be often made with great accuracy. A comprehensive list of Hammett $\sigma$ constants is available (Hansch et al., 1991) from where the data for the functional groups in this study were taken.

In Tab. 3, linear parameters as well as correlation coefficients $\mathrm{R}$ obtained from linear regression can be found for para substituted phenols, while analogous results for meta substituted derivatives are presented in Tab. 4 .

In case of ionization potentials vs. Hammett constant dependence, the values for meta-amino and meta-dimethylamino phenol were significantly off the linear trend and therefore they were omitted. Without neglecting these data, correlation coefficients would be of 0.853 in water, 0.884 in benzene

Tab. 3. Regression parameters for Hammett correlation $\left(y=\mathrm{a} \cdot \sigma_{\mathrm{p}}+\mathrm{b}\right)$ in para derivatives.

\begin{tabular}{lccc|ccc|ccc}
\hline Environment & \multicolumn{3}{c|}{ Water } & \multicolumn{3}{c|}{ Benzene } & \multicolumn{3}{c}{ Gas } \\
$\boldsymbol{y}=$ & BDE & PA & IP & BDE & PA & IP & BDE & PA & IP \\
\hline $\mathbf{a} / \mathbf{k J ~ m o l}^{-1}$ & $53(4)$ & $-26(3)$ & $105(6)$ & $40(3)$ & $-55(6)$ & $125(8)$ & $36(3)$ & $-70(8)$ & $133(9)$ \\
$\mathbf{b} / \mathbf{k J ~ m o l}^{-\mathbf{1}}$ & $365(2)$ & $156(2)$ & $649(3)$ & $357(2)$ & $465(3)$ & $678(4)$ & $361(2)$ & $1431(4)$ & $788(5)$ \\
$\mathbf{R}$ & 0.968 & 0.919 & 0.974 & 0.967 & 0.931 & 0.972 & 0.967 & 0.918 & 0.964 \\
\hline
\end{tabular}


Tab. 4. Regression parameters for Hammett correlation $\left(y=\mathrm{a} \cdot \sigma_{\mathrm{m}}+\mathrm{b}\right)$ in meta derivatives.

\begin{tabular}{lccc|ccc|ccc}
\hline Environment & \multicolumn{3}{c|}{ Water } & \multicolumn{3}{c|}{ Benzene } & \multicolumn{3}{c}{ Gas } \\
$\boldsymbol{y}=$ & $\mathbf{B D E}$ & $\mathbf{P A}$ & $\mathbf{I P}$ & $\mathbf{B D E}$ & $\mathbf{P A}$ & IP & BDE & PA & IP \\
\hline $\mathbf{a} / \mathbf{k J ~ m o l}^{-\mathbf{1}}$ & $26(2)$ & $-25(2)$ & $74(7)$ & $18(1)$ & $-64(4)$ & $109(11)$ & $15(2)$ & $-86(6)$ & $132(14)$ \\
$\mathbf{b} / \mathbf{k J ~ m o l}^{-1}$ & $375,4(6)$ & $160,2(5)$ & $661(3)$ & $367,9(4)$ & $478(2)$ & $686(4)$ & $370,2(6)$ & $1449(3)$ & $794(6)$ \\
$\mathbf{R}$ & 0.981 & 0.981 & $0.943^{*}$ & 0.979 & 0.975 & $0.940^{*}$ & 0.945 & 0.970 & $0.925^{*}$ \\
\hline
\end{tabular}

*values for $\mathrm{NH}_{2}$ and $\mathrm{NMe}_{2}$ derivatives were omitted

Tab. 5. Optimized (M06-2X/6-311++ $\left.\mathrm{G}^{* *}\right)$ phenolic $\mathrm{C}-\mathrm{O}$ bond length in various environments and Hammett substituent constants (Hansch et al., 1991).

\begin{tabular}{|c|c|c|c|c|c|c|c|c|}
\hline \multirow{2}{*}{$X$} & \multicolumn{3}{|c|}{$\operatorname{Meta} \mathbf{d}(\mathrm{C}-\mathrm{O}) / \AA$} & \multicolumn{3}{|c|}{$\operatorname{Para} d(C-O) / \AA$} & \multirow{2}{*}{$\sigma_{\mathrm{m}}$} & \multirow{2}{*}{$\sigma_{\mathrm{p}}$} \\
\hline & Water & Benzene & Gas & Water & Benzene & Gas & & \\
\hline Br: & 1.3670 & 1.3570 & 1.3591 & 1.3687 & 1.3582 & 1.3603 & 0.39 & 0.23 \\
\hline $\mathbf{C F}_{3}:$ & 1.3664 & 1.3563 & 1.3580 & 1.3629 & 1.3540 & 1.3562 & 0.43 & 0.54 \\
\hline Cl: & 1.3670 & 1.3571 & 1.3589 & 1.3692 & 1.3588 & 1.3609 & 0.37 & 0.23 \\
\hline CN: & 1.3656 & 1.3553 & 1.3573 & 1.3589 & 1.3515 & 1.3542 & 0.56 & 0.66 \\
\hline F: & 1.3668 & 1.3569 & 1.3591 & 1.3729 & 1.3615 & 1.3637 & 0.34 & 0.06 \\
\hline Me: & 1.3735 & 1.3616 & 1.3633 & 1.3757 & 1.3630 & 1.3644 & -0.07 & -0.17 \\
\hline MeCO: & 1.3696 & 1.3585 & 1.3600 & 1.3610 & 1.3540 & 1.3563 & 0.38 & 0.50 \\
\hline MeO: & 1.3709 & 1.3602 & 1.3618 & 1.3737 & 1.3656 & 1.3673 & 0.12 & -0.27 \\
\hline $\mathrm{MeSO}_{2}:$ & 1.3640 & 1.3551 & 1.3571 & 1.3582 & 1.3521 & 1.3544 & 0.60 & 0.72 \\
\hline $\mathrm{NH}_{2}:$ & 1.3735 & 1.3612 & 1.3630 & 1.3814 & 1.3678 & 1.3690 & -0.16 & -0.66 \\
\hline $\mathrm{NMe}_{2}:$ & 1.3752 & 1.3627 & 1.3647 & 1.3784 & 1.3657 & 1.3671 & -0.16 & -0.83 \\
\hline $\mathrm{NO}_{2}:$ & 1.3634 & 1.3542 & 1.3562 & 1.3531 & 1.3492 & 1.3522 & 0.71 & 0.78 \\
\hline OH: & 1.3703 & 1.3596 & 1.3613 & 1.3781 & 1.3656 & 1.3671 & 0.12 & -0.37 \\
\hline Ph: & 1.3721 & 1.3608 & 1.3626 & 1.3713 & 1.3601 & 1.3620 & 0.06 & -0.01 \\
\hline$t$-But: & 1.3748 & 1.3625 & 1.3642 & 1.3749 & 1.3627 & 1.3639 & -0.10 & -0.20 \\
\hline $\mathbf{H}$ & 1.3727 & 1.3609 & 1.3626 & 1.3727 & 1.3609 & 1.3626 & 0.00 & 0.00 \\
\hline
\end{tabular}

and 0.901 in gas phase. In case of para derivatives and proton affinities, the relationship excluding values for dimethylamino and unsubstituted phenol provided significantly better correlation coefficient of 0.962 in benzene. It should be mentioned that the interval of published $\sigma_{\mathrm{p}}$ values for the dimethylamino group is one of the largest ones and even a value with a relatively high standard error of $-0.6 \pm 0.2$ has been suggested (Jaffé, 1953). Moreover, in case of $\mathrm{NMe}_{2}$ compared to the vast majority of substituents, an exceptionally large charge transfer with $\mathrm{OH}$ group was observed (Nazarparvar, 2012). Apart from these exceptions, our correlations involved all 15 derivatives and the value for unsubstituted phenol. Considering this number of points for statistics, the found correlation coefficients can be regarded as satisfactory.

Alternative descriptor in case of monosubstituted phenols seems to be the length of phenolic $\mathrm{C}-\mathrm{O}$ bond which was found to be sensitive to the substituent both in para and meta positions. Also, the higher the value of the Hammett constant, the shorter the $\mathrm{C}$ - $\mathrm{O}$ bond becomes. These lengths obtained from the optimized geometries are presented in Tab. 5 and potentially can be also obtained from X-ray diffraction experiments.

When the bond length is used for correlations, unlike Hammett constants, the values for meta and para derivatives lie on a single line. Especially good linearity ( $\mathrm{R}=0.989$ ) was found for the relationship between 31 values of proton affinities in water and $d(\mathrm{C}-\mathrm{O})$ bond lengths optimized in water. The linear equation reads:

$$
\begin{gathered}
\mathrm{PA} / \mathrm{kJ} \mathrm{mol}^{-1}= \\
=-2.13(7) \cdot 10^{3}+1.67(5) \cdot d(\mathrm{C}-\mathrm{O}) / \AA
\end{gathered}
$$

This equation potentially enables relevant prediction of solvent based PAs. For phenol derivatives, this kind of experimental data is still scarce.

\section{Conclusion}

In this paper, results of quantum chemical thermodynamics calculations have supported the viability of the newer hybrid M06-2X functional. Theoretical reaction enthalpies tend to be slightly underes- 
timated with respect to the experimental absolute values, but substituent induced changes are well predicted by the present method. Based on the presented correlations it can be concluded that the DFT/M06-2X method with employed Pople type basis set $6-311++\mathrm{G}(\mathrm{d}, \mathrm{p})$ provides thermodynamic values in good agreement with experimental data. No considerable major differences between B3LYP and M06-2X were found in terms of correlation slopes, but the B3LYP functional tends to provide slightly more shifted values. Therefore, the Minnesota 06 hybrid functional which has become widely adopted in recent years seems to be a reasonable alternative to the robust and most popular B3LYP one.

\section{Acknowledgement}

We are grateful to the HPC center at the Slovak University of Technology in Bratislava, which is a part of the Slovak Infrastructure of High Performance Computing (SIVVP project, ITMS code 26230120002, funded by the European region development funds, ERDF) for the computational time and resources made available.

\section{References}

Becke AD (1988) Phys. Rev. A. 38: 3098.

Bordwell FG, Cheng J (1991) J. Am. Chem. Soc. 113: 1736-1743.

Chen Y, Xiao H, Zheng J, Liang G (2015) PLoS One, 10: e0121276.

Francl MM, Pietro WJ, Hehre WJ, Binkley JS, Gordon MS, DeFrees DJ, Pople JA (1982) J. Chem. Phys. 77: 3654-3665.

Frisch MJ, Trucks GW, Schlegel HB, Scuseria GE, Robb MA, Cheeseman JR, Scalmani G, Barone V, Petersson GA, Nakatsuji H, Li X, Caricato M, Marenich AV, Bloino J, Janesko BG, Gomperts R, Mennucci B, Hratchian HP, Ortiz JV, Izmaylov AF, Sonnenberg JL, Williams-Young D, Ding F, Lipparini F, Egidi F, Goings J, Peng B, Petrone A, Henderson T, Ranasinghe D, Zakrzewski VG, Gao J, Rega N, Zheng G, Liang W, Hada M, Ehara M, Toyota K, Fukuda R, Hasegawa J,
Ishida M, Nakajima T, Honda Y, Kitao O, Nakai H, Vreven T, Throssell K, Montgomery JA Jr., Peralta JE, Ogliaro F, Bearpark MJ, Heyd JJ, Brothers EN, Kudin KN, Staroverov VN, Keith TA, Kobayashi R, Normand J, Raghavachari K, Rendell AP, Burant JC, Iyengar SS, Tomasi J, Cossi M, Millam JM, Klene M, Adamo C, Cammi R, Ochterski JW, Martin RL, Morokuma K, Farkas O, Foresman JB and Fox DJ (2016) Gaussian 16, Revision B.01, Gaussian, Inc. Wallingford CT.

Fujio M, McIver Jr RT, Taft RW (1981) J. Am. Chem. Soc. 103: 4017-4029.

Hammett LP (1937) J. Am. Chem. Soc. 59: 96-103.

Hansch C, Leo A, Taft RW (1991) Chem. Rev. 91: 165-195.

Hariharan PC, Pople JA (1973) Theor. Chim. Acta. 28: 213-222.

Huang F, Jiang J, Wen M, Wang ZX (2014) J. Theor. Comput. Chem. 13: 1350074.

Jaffé HH (1953) Chem. Rev. 53: 191-261.

Klein E, Lukeš V (2006a) J. Phys. Chem. A, 110: 1231212320

Klein E, Lukeš V (2006b) J. Mol. Struct.(THEOCHEM) 767: 43-50.

Klein E. Lukeš V (2006c) Chem. Phys. 330: 515-525.

Klein E, Rimarcik J, Lukes V (2009) Acta Chim. Slovaca, 2: $37-51$.

Lee C, Yang W, Parr RG (1988) Phys. Rev. B. 37: 785.

Luo S, Zhao Y, Truhlar DG (2011) Phys. Chem. Chem. Phys. 13: 13683-13689.

Marenich AV, Cramer CJ, Truhlar DG (2009) J. Phys. Chem. B. 113: 6378-6396.

Michalík M, Vagánek A, Poliak P (2014) Acta Chim. Slovaca. 7: 123-128.

Nazarparvar E, Zahedi M, Klein E (2012) J. Org. Chem. 77: 10093-10104.

Peverati R, Truhlar DG (2011) J. Phys. Chem. Lett. 2: 2810-2817.

Rassolov VA, Pople JA, Ratner MA, Windus TL (1998) J. Chem. Phys. 109: 1223-1229.

Rimarčík J, Lukeš V, Klein E, Rottmannová L (2011) Comp. Theor. Chem. 967: 273-283.

Škorňa P, Lengyel J, Rimarčík J, Klein E (2014) Comput. Theor. Chem. 1038: 26-32.

Vagánek A, Rimarcik J, Lukes V, Rottmannová L, Klein E (2011) Acta Chim. Slovaca 4: 55-71.

Zhao Y, Truhlar DG (2008) Theor. Chem. Acc. 120: 215-241. 